esther Cohen

elsA r. B rondo

\title{
Presentación
}

\section{Introduction by the editors}

\section{Dossier}

El artículo que abre este número de la revista Acta Poetica, "Viaje de Moscú a Petersburgo. Petersburgo, eje semántico de la literatura rusa", está dedicado a la fundación de San Petersburgo (1703) como detonante de la modernidad cultural rusa. Escribe Tatiana Bubnova, "la cultura rusa clásica, la del siglo xix , aquella que le dio al mundo a Tolstoi y Dostoievski, a Gógol y Pushkin, a Goncharov y Chéjov, a Tchaikovski y Musorgski [...] se asocia y se edifica a partir de y en presencia de San Petersburgo". En el sigloxviii , Pedro I traslada la capital de Rusia a esta ciudad, que reivindica su pertenencia a Europa y transforma radicalmente la cultura, la técnica y la ideología del país.

La tradicional y religiosa Moscú fue desplazada por una capital "más joven / la vieja Moscú perdió su brillo, / como la viuda porfirogéneta / ante una nueva reina", como escribiera Pushkin. Paradójicamente, el esplendor de San Petersburgo, que abría la ventana a un nuevo imaginario, fue construido con el sacrificio de miles de "siervos mártires, cuyas vidas fueron gastadas con un despilfarro verdaderamente faraónico [...], sobre los terrenos pantanosos del delta del río Neva”. La belleza de esa ciudad llevaba consigo desde su surgimiento la semilla de su paradójica existencia: ser a la vez un lugar privilegiado para la cultura y, al mismo tiempo, como escribirá más tarde Ósip Mandelstam, "Petersburgo es el abismo, el dominio demoníaco, la muerte". 
Si bien San Petersburgo fue una ventana a Occidente, capaz de dar vida a una buena parte de la literatura clásica rusa, este sueño de Pedro el Grande produjo también sus parias, retratados en los cuentos y novelas de Gógol y Dostoievski. Hombres marginados, con vidas pequeñas que recorrieron las calles de la capital como seres fantasmales. La literatura que se escribió del siglo xviii al xix en Rusia fue una especie de conciencia nacional y, por tanto, ocupó también el lugar de la política, la filosofía y la vida social.

En 1917, año del estallido de la revolución bolchevique, como menciona Tatiana Bubnova, "la literatura rusa no muere [...]. Lo que termina es el período de la centralidad petersburguense tan rica en sentidos y matices. Si Pedro el Grande, a costa de gigantescos sacrificios y de sobrehumanos esfuerzos del pueblo, trasladó la capital a las orillas del Báltico, abriendo el país al influjo de Europa, Lenin, en cambio, cerró cuidadosamente la ventana y movió la capital de regreso a los principios y símbolos de Moscú; lejos de la contaminación de los vientos europeos, a pesar de los sueños de la revolución mundial que formaban parte de su ideario".

Esta extraordinaria introducción a toda una época majestuosa de la historia rusa y de esta ciudad, desconocida para el lector latinoamericano, ocupa con justicia un lugar privilegiado en nuestras páginas.

\section{Varia}

Si la ambigüedad acompaña a todo documento de cultura, como lo muestra el artículo del Dossier, los textos que forman esta segunda parte no escapan a la misma reflexión. Astrid Deuber-Mankowsky emprende una crítica sin tregua a las tesis sobre la modernidad, que plantea el filósofo italiano Giorgio Agamben en Homo Sacer. A partir del concepto de la "nuda vida", tomado de la experiencia de los campos de exterminio, Agamben construye la tesis de que "el estado de excepción" (Auschwitz) se ha convertido en el nomos del mundo actual. La autora hace un severo análisis de la influencia del pensamiento de Carl Schmitt, quien considera que la verdad aparece sólo en los extremos, en el estado de excepción. Deuber-Mankowsky se enfrenta al pensamiento 
de Agamben y a su cercanía con el ideólogo del nazismo, que hace de la figura del "musulmán"l la metáfora de toda posibilidad de conocimiento. En este artículo se contrasta la noción de biopolítica de Foucault a este aporético uso de las ideas de Schmitt en Homo Sacer de Agamben.

Resulta polémico que uno de los pensadores más leídos en el campo de la filosofía, haga uso de un pensamiento que debería ser combatido. La publicación de este artículo contribuye a una discusión necesaria que opone resistencia ante un autor, Agamben, quien tiene una notable influencia en el pensamiento filosófico contemporáneo.

El artículo de Diego Sheinbaum, "J.M. Coetzee: en el callejón de Samuel Beckett", recorre las influencias de la literatura en la obra de Corete. En una conferencia titulada "Homage", Coetzee escribe y Diego Sheinbaum parafrasea, "no fueron los escritores sudafricanos quienes le enseñaron a sentir y a responder a la situación en su país, sino Rilke y Musil, Ford y Pound, Zbiniew Herbert y Beckett; es decir, una pléyade de escritores modernistas". De todos ellos, Sheinbaum privilegia a Samuel Beckett de donde Coetzee toma el solipsismo de sus personajes. Sin embargo, como anota el autor, "se trata de un viaje desde el encierro en el monólogo del ego hasta el intento de reconocer otras voces, otras conciencias, con el afán de ir más allá de la negación y la violencia”. En la literatura del sudafricano Coetzee el colonialismo es central y este elemento irrumpe y asedia a sus personajes, para mostrar al lector el peligro de no reconocer a los otros, en una sociedad en donde las desigualdades son tan cruelmente expuestas: hablamos de Sudáfrica, pero también del mundo.

En el artículo de Jacobo Sefamí, "De la desesperanza a la plenitud: la revelación epifánica en la poesía de Álvaro Mutis", el autor aborda la poesía de Mutis a partir de la idea de epifanía como motor que unifica el accionar poético. Frente a la desesperanza que aparece en gran parte de la obra del poeta colombiano, el concepto de epifanía (entendido como una categoría estética, acuñada por Joyce) es ese instante frágil y fugaz en donde "Sólo una palabra. / Una palabra y se inicia la danza / de una

${ }^{1}$ Primo Levi, en su libro Los hundidos y los salvados, menciona por vez primera al "musulmán". Tipo de personaje de los campos de exterminio, vacío de voluntad y conciencia; un muerto en vida producido por el aparato genocida del nazismo. 
fértil miseria". Como señala Sefamí, "la condición infeliz de la existencia es infructuosamente aliviada por la vigilancia de la voz poética". Mutis se debate entre la conciencia del desamparo, el exilio, y la poesía como revelación apocalíptica. La epifanía revela la totalidad del caos del mundo, pero ese caos no es azaroso para el poeta que la observa.

Para cerrar la sección de Varia, Melina Balcázar, en su artículo "Muerte y traducción en la escritura de Pascal Quignard", aborda el problema de la traducción en este escritor francés, que parte de la idea de que traducir es "Ayudar a hablar al muerto". El artículo explora la postura de Quignard frente a una tarea imposible, traer fielmente las palabras de otra lengua a la propia. Para él la traducción es antes que nada una cuestión de energeia, que se produce en la confrontación de las lenguas; para traducir es necesario, según Quignard, "repetir el texto — no como tal-, sino su fuerza". Se trata así de una práctica de la traducción palabra por palabra que hace que la lengua materna se vuelva extranjera. La obra del escritor y músico está atravesada por la profunda relación entre la lengua y la muerte, de la misma manera que en su libro, Todas las mañanas del mundo, se sumerge en la música para encontrar en ella la forma privilegiada de comunicación con los muertos. Quignard afirma: "escribo para algunos pocos lectores. Escribo para los muertos, para aquellos que decidieron no hablar, para los autistas".

\section{Apuntes}

Annunziata Rossi, en su erudito trabajo sobre el primer Manierismo toscano y Pier Paolo Pasolini, señala: "del genio de los manieristas, sus contemporáneos no se dieron cuenta. Considerado más bien como amaneramiento, imitación de los tres grandes y decadencia del Renacimiento, el Manierismo caerá pronto en un olvido que durará siglos hasta ser redescubierto y evaluado en la primera mitad del siglo $\mathrm{xx}$, en el que serán subrayadas sus afinidades con el nuevo tiempo: desarraigo del intelectual, pérdida de los valores sociales, crisis política y religiosa". Pasolini es uno de los intelectuales deslumbrados por el legado manierista, que integra a su multidisciplinaria obra. Rossi nos lleva de la mano por la historia de esta escuela de la pintura italiana hasta la figura 
de Pasolini, atravesado él mismo por el espíritu desencantado de los tiempos que le tocaron vivir.

Con un apunte en homenaje al filósofo Gilles Deleuze, quien este año cumple 20 años de haber fallecido, cerramos este número. Esther Cohen dedica un entrañable escrito a Deleuze. El filósofo del devenir y la experimentación murió después de arrojarse por la ventana del cuarto piso, tras una larga batalla contra su enfermedad. La autora se pregunta si actualmente podemos seguir pensando en las líneas de fuga propuestas por la filosofía deleuziana, o si su suicidio cancela esta posibilidad. A partir del duelo, que se reconoce como permanente, también se lee la vigencia y necesidad del pensamiento de Deleuze. Es decir, si se temía por el futuro del pensamiento deleuziano sin Deleuze, las líneas de fuga - que tanto fascinaron a este pensador - siguen siendo hasta la fecha la única "experiencia posible". 